Article

\title{
Narrative Perspectives on Self-Directed Foreign Language Learning in a Computer- and Mobile-Assisted Language Learning Context
}

\author{
Daniel R. Isbell *, Hima Rawal, Rachelle Oh and Shawn Loewen \\ Second Language Studies, Michigan State University, 619 Red Cedar Road, East Lansing, MI 48824, USA; \\ rawalhim@msu.edu (H.R.); frazi102@msu.edu (R.O.); loewens@msu.edu (S.L.) \\ * Correspondence: isbellda@msu.edu; Tel.: +1-517-353-0740
}

Academic Editors: Sonia Rocca and Bryan Smith

Received: 14 January 2017; Accepted: 12 April 2017; Published: 21 April 2017

\begin{abstract}
Millions of learners around the world use self-directed computer- and mobile-assisted language learning (CALL, MALL) programs to study foreign languages. One such program, Duolingo, currently attracts over 120 million users and is claimed (by the publisher) to be a highly effective method of language learning. While L2 researchers have shown limited engagement with similar large-scale commercial programs, issues related to learner persistence, motivation, and program efficacy have been reported. This study investigates the experiences and efficacy of learning Turkish on Duolingo for 12 weeks, drawing on a methodological tradition of researcher narratives. Three graduate student researchers kept diaries and completed weekly reflections on their Turkish learning experiences, which served as source material for individual narrative analysis. The resulting narratives were discussed and analyzed collaboratively from an ecological perspective. Strategies used by the researcher-participants were heavily influenced by ecological factors. Persistence in learning was found to be influenced by ecological factors and varied across timescales. Ultimately, the researcher-participants had limited Turkish learning outcomes and felt demotivated to continue studying on Duolingo. Implications for CALL/MALL design include presenting materials in a meaningful context, capitalizing on social affordances, and providing meaningful feedback to learners in order to facilitate learning and goal-setting.
\end{abstract}

Keywords: CALL; Duolingo; MALL; narrative analysis; self-directed language learning; Turkish

\section{Introduction}

In 1934, the German linguist-in-exile Leo Spitzer published a three-part essay titled "Learning Turkish" [1]. His observations came from his time living and learning in Istanbul. Describing his experience with the language, he wrote:

I enjoyed Turkish only after reading some pages from a thin but well-written book. Literature gave me a better sense of the life of this language than did studies of syntax or impoverished conversations I had with people on the street. [1] (p. 769)

While the time and place are different, like Spitzer, three participants in this study have reflected on a Turkish learning experience. More specifically, this study presents the autobiographic narratives of three researcher-participants in their initial 12-week attempt to learn Turkish as a foreign language in the 21st century. While Spitzer relied on dictionaries, linguistic descriptions, novels, and interactions with Turkish speakers to learn the language, the researcher-participants selected a different approach, namely Duolingo (Duolingo, Inc., Pittsburg, PA, USA, www.duolingo.com), a self-directed language learning program used by over 120 million people around the world for learning 21 different languages [2]. 


\subsection{Narrative Research in Language Learning}

Narrative research, broadly defined as research in which stories play a predominant role, has received increased interest in second language (L2) learning and teaching in recent years [3-5]. Autoethnography is a related approach which has influenced narrative research, and indeed, methodological overlap exists between the two approaches. Narrative research has its origin in dialogic interactions, when narrative data were collected mostly through interviews, which were believed to provide the researcher with participant-based, subjective experiences and emic perspectives. However, data collection is no longer confined to interviews [5] and multiple data sources are now used (e.g., diaries and journals, semi-structured interviews, e-mail exchanges). The narrative approach has been used as a framework to tell the stories of learners regarding their language learning experiences. Such stories reveal both the "lived" and "imagined" experiences of the story tellers in which "learners [tell] about their experiences of learning and using languages" [4] (p. 450). Lived experiences represent actual events and travails in the process of learning a new language. On the other hand, imagined experiences represent learners' dreams and expectations.

Early narrative work focused mainly on content analysis and the analysis of themes extracted from the data. However, more recent narrative research has focused on broader sociopolitical discourses, local contexts of participants' lives, and the immediate story-telling context [4]. The current study focuses on one genre of narrative research, the researcher narrative, which has yielded many important insights on language learning. Through the linguistic expertise of researcher-participants, these autobiographic narratives generate rich insights on the affective factors and learning strategies that play a role in language learning as it is happening by eliciting data that are often otherwise inaccessible [6]. Among researcher narratives, it is perhaps Schmidt (researcher-participant) and Frota's (co-researcher and target language expert) seminal 1986 study that has had the largest impact on the field of second language acquisition (SLA), introducing the noticing hypothesis [7]. While Schmidt and Frota's narrative had a cognitive orientation and focused mainly on the acquisition of linguistic features, narrative research has also adopted ecological [8], sociocultural [9], and pragmatic perspectives [10]. Thus, narrative research has demonstrated flexibility as a tool for investigating diverse questions from a variety of perspectives. Like all narratives, researcher-narratives run the risk of becoming "polished accounts of who we are" [11] (p. 372), but through reflexive practice researchers can mitigate the potential for idealization while richly describing and explaining language learning experiences.

\subsection{Language Learning Researcher Narratives: Approaches and Foci}

Language learning researcher narratives have a long and fruitful history, which is selectively recounted here. As previously mentioned, the influential noticing hypothesis emerged three decades ago from Schmidt's study of Portuguese during a five-month stay in Brazil [7]. Schmidt's diary entries documented his language learning in an instructed context and his personal reactions to the instruction over time. Schmidt also detailed his personal learning strategies and approach to learning the language. In a similar researcher narrative, Grabe and Stoller [12] reported on Grabe's Portuguese learning over a five-month stay in Brazil. Grabe, an L2 reading researcher, focused on vocabulary learning and the development of his L2 reading competence. The study included pre- and post-tests, detailed Grabe's approach and habits, and revealed a number of specific vocabulary learning strategies. In another South American excursion by an L1 English researcher, Carson and Longhini [13] told the story of Carson achieving conversational competence through informal learning. Carson and Longhini's focus was on the language learning strategies employed by Carson, taking advantage of her keen knowledge in this area in recording diary entries for later analysis. 
More recent researcher narratives have continued to be concerned with the acquisition of linguistic features and use of learning strategies, but they have arguably also shown greater sensitivity to the learning environment and emphasized learners' subjective experiences. In a narrative tracking, the acquisition of a single Japanese word (saiketsu, 'to draw blood'), Churchill [14] carefully documented how a series of life events, beginning with a hospitalization, led to dynamic and multi-faceted acquisition of the lexical item. Churchill was keenly sensitive to the environment's role as he acquired various pieces of lexical knowledge over the course of three months. Also looking towards Japan, Simon-Maeda [9] and Casanave [8] present narratives of language learning and use spanning many years. Both researcher-participants reflect on the interactions among their social positioning as foreign women, communities of practice, and language learning. Communication strategies are also described in detail, as well as the researchers' broader orientations and approaches to learning. Other researcher narratives have focused on identity and motivation. Bringing a unique (non-linguistic) expertise in organizational behavior to the language learning researcher narrative, Winkler [15] recounts his learning of Danish and the dynamic (re) construction of identity in a university across the border from his home in Germany. Winkler was able to illustrate how his larger language learning narrative could be characterized in seven different ways, ranging from resistance to Danish to being genuinely interested in it. Change over his three and a half years of Danish learning stemmed from motivational shifts and social influences.

Examining Chinese learning, Duff et al. [10] carried out one of the most ambitious language learning researcher narrative projects to date. Including five learners, Duff and her colleagues constructed and co-constructed narratives based on their years of experience learning Chinese. The resulting book-length report includes chapters on developing Chinese proficiency, their approaches towards becoming literate in Chinese, and negotiating their Chinese learning, research communities, and personal identities. Distinguishing this work from most researcher narratives, Duff et al. embraced cross-case comparisons and co-construction of their Chinese learning experiences [10].

Despite these studies' diverse foci (e.g., strategies, linguistic items, identity), one commonality uniting these researcher narratives is an immersion context for learning. Schmidt and Grabe went to Brazil, Carson spent time in Argentina, Churchill and Simon-Maeda were long-term residents of Japan, Casanave spent an extended period of time working in Japan, and Winkler worked in a Danish university. Leo Spitzer, too, lived in Turkey when he learned the language. While Duff and her colleagues reported on their learning experiences in foreign language contexts, they all had spent time in Chinese-dominant locales as well.

Fewer researcher narratives have examined foreign language learning, let alone in a self-directed computer-assisted language learning (CALL) context. One such study, Clark and Gruba [16], documents Clark's four-week experience learning Korean on Livemocha (now defunct, formerly www. livemocha.com). Adopting an ecological perspective that gives careful consideration to contextual influences, similar to researchers in immersion-based studies, Clark's (researcher-participant) motivation, frustration, and demotivation emerged from thematic analysis of his diary entries and debriefing conversations with Gruba (co-researcher). In terms of motivation, Clark responded positively to communicating with other language learners on the site and enjoyed being able to help people learn English. He also found satisfaction through task completion, which Livemocha highlighted with progress bars and points to accumulate. However, frustrations outweighed these motivating features. Decontextualized grammar exercises, limited interactivity in lessons, lack of instruction on the Korean script and pronunciation, and inaccurate advice from other users all discouraged Clark, which led to demotivation. Clark also noted personal responsibilities and feeling "dislocated from other users" (p. 170) as other demotivating factors. What Clark experienced is not uncommon in self-directed CALL. 


\subsection{Questions and Challenges for Self-Directed CALL and MALL}

Learning a foreign language in one's spare time is an attractive proposition, and many self-directed CALL programs have aimed to facilitate this [17]. The opportunities presented by self-directed language learning programs is made even more attractive through mobile-assisted language learning (MALL), which has also been referred to as mobile language learning (MoLL) [18]. MALL focuses on the "out-of-class applications" of mobile devices used to study a second language [19], and it has made language study possible wherever and whenever one desires, taking advantage of personal computers and portable technology like smartphones, tablet computers, media players, and so on $[20,21]$. At the same time, commercial language learning programs, including Rosetta Stone (Rosetta Stone Inc., Arlington, VA, USA, http:/ / www.rosettastone.com), Busuu (busuu Ltd., London, UK, https://www.busuu.com), Babbel (Lesson Nine GmbH, Berlin, Germany, https://www.babbel.com/), and Duolingo, have become numerous and present the hopeful spare-time language learner a wide array of conventional CALL as well as newer MALL options. Although these programs attract millions of users, SLA researchers have so far shown limited engagement with this sort of language learning. However, such engagement is imperative if instructed SLA (ISLA) researchers are to have any impact on such popular language learning programs. At the same time, investigating language learning in MALL contexts could support or potentially expand ISLA theories.

The effectiveness of these commercial online language learning programs is unclear. Research commissioned by program developers has found favorable language learning outcomes for users (e.g., [22,23]), leading to some claims that these programs offer greater effectiveness than face-to-face foreign language courses. Independent research on these programs focusing on learner outcomes has been limited, but so far has been less optimistic. Based on standardized test scores, Lord [24] found $45 \mathrm{~h}$ of Rosetta Stone offered no advantages over an in-person introductory Spanish course; the Rosetta Stone users also struggled much more in oral interviews with the researcher and frequently resorted to using English. Nielsen's [25] most dramatic finding was that professionals employed by the U.S. government were extremely unlikely to persist in using Rosetta Stone and Auralog's TELL ME MORE (Paris, France, now Rosetta Stone) which made it impossible to collect enough data to analyze proficiency gains. The publisher-commissioned research also reported issues with user persistence, though to a somewhat lesser degree [22,23]. These findings echo the difficulties Clark faced in his attempt at learning Korean on Livemocha [16].

\section{Materials and Methods}

Duolingo, founded in 2011, now boasts over 120 million users [26]. Although one of its founders, Luis von Ahn, recently stated that Duolingo works better as a supplement to in-person formal instruction [27], Duolingo's website still makes strong claims of its effectiveness (and even superiority) as a stand-alone language learning experience [26]. Following a long tradition of researcher narratives in language learning and addressing a general lack of research engagement with popular commercial self-directed CALL and MALL programs, this study addressed the following research question: what shapes the experiences and efficacy of learning a foreign language (i.e., Turkish) on Duolingo?

In doing so, we adopted an ecological perspective shared by Clark and Gruba [16], Churchill [14], and Casanave [8], which "compels us to reconceptualize learning as always and everywhere contextualized" [28] (pp. 24-25). We sought to integrate our learning experience with program interactions, our project team members, and the events of our lives, which made this study relational [29]. In addition, researcher-participants' self-reflection on the language learning process and our mutual collaboration align with the reflexive element of the ecological perspective [29]. 


\subsection{The Challenge}

This study developed as part of a larger project investigating ab initio foreign language learning with Duolingo. As an experiential component of an ISLA graduate seminar, a group of nine graduate students in Teaching English to Speakers of Other Languages (TESOL) and Second Language Studies and their professor agreed to study Turkish on Duolingo for a minimum of one hour a week and a maximum of $34 \mathrm{~h}$ during one semester. These participants were all experienced language learners who possessed knowledge of second language acquisition and pedagogy; this purposive sample of adult learners was selected to bias for the best in terms of learning outcomes. The 34-h target was based on the average number of Duolingo hours claimed by Vesselinov and Grego [23] to be equivalent to one semester of an in-person university language course. This target also reflects the design of other studies examining self-directed language learning programs (e.g., [23-25]) which investigated learning outcomes after a predetermined period of study time (e.g., 45 h, $200 \mathrm{~h}$ ). Turkish was chosen because no participant had any prior experience with the language or knowledge of a closely-related language (e.g., Uzbek), and the group had access to a native speaker instructor of Turkish at the university.

All members of the group agreed to keep time logs of their Duolingo use and journals of their learning experience, and also agreed to limit their Turkish study to Duolingo's resources (i.e., no additional textbooks or other external resources). Additionally, after 12 weeks of study, all group members, regardless of total study time, took a Turkish 101 final exam (a four-skill exam, with a passing score of 70\%) supplied and graded by the university's Turkish instructor. Those who had not yet reached $34 \mathrm{~h}$ by the time of the final exam had the option to retake the exam again, after completion of the $34 \mathrm{~h}$.

\subsection{The Duolingo Environment}

Duolingo is a self-directed language learning program that presents clusters of skills (e.g., phrases, adjectives, food) which are divided into lessons (e.g., two lessons on adjectives). These skills are presented in a mostly linear order with learners advancing to new skills only upon completion of prior lessons. Duolingo is accessible on both desktop computers (CALL) via web interface (Figure 1) and on mobile devices (MALL) through the Duolingo app. Activities common across the platforms include L1-L2/L2-L1 translations (Figure 2), multiple-choice translations, and dictation. For the Turkish course, oral repetition exercises are accessible only on the desktop web interface, while vocabulary translation matching is an app-only feature. Both platforms have a word translation feature, available by mouse-over on the computer or finger tap on the mobile, to support many of the activities. On the desktop web interface only, there is limited explicit grammar information on the splash page for each skill. In addition, explicit corrective feedback is provided when learners commit errors during the lessons. Learners have the option of reviewing individual lessons immediately upon completion, or at any time thereafter. Duolingo's feedback is typical of language learning programs, where feedback is limited to "displaying a correct answer or indicating a 'right/wrong' evaluation" [30] (p. 347). Duolingo also incorporates some social networking features, such as the ability to follow friends' progress and post discussion board comments on sentences used in learning activities (Figure 3). Duolingo takes a gamified approach to teaching a language. Learners earn experience points (XP) for completing lessons, which leads to leveling up. Learners can also earn "lingots" (Duolingo's currency) by building "streaks" (consecutive days of study) and completing skills. The lingots can be used to unlock additional features (e.g., Timed Practice mode) or buy cosmetic flair for Duo, the cartoon owl mascot of the program. 


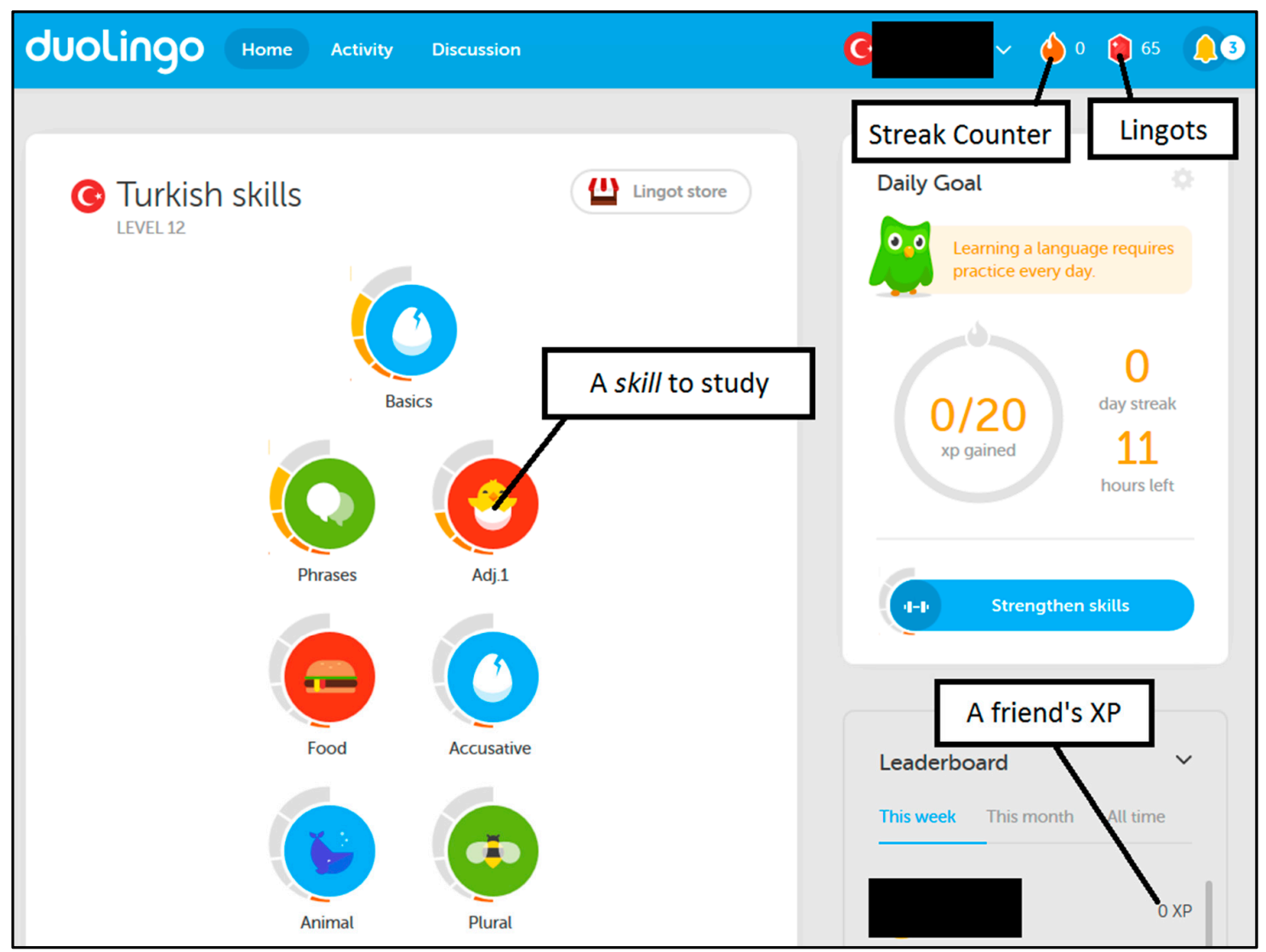

Figure 1. Duolingo (Duolingo, Inc., Pittsburg, PA, USA, www.duolingo.com) home screen. Screenshot used with permission from Duolingo, Inc.

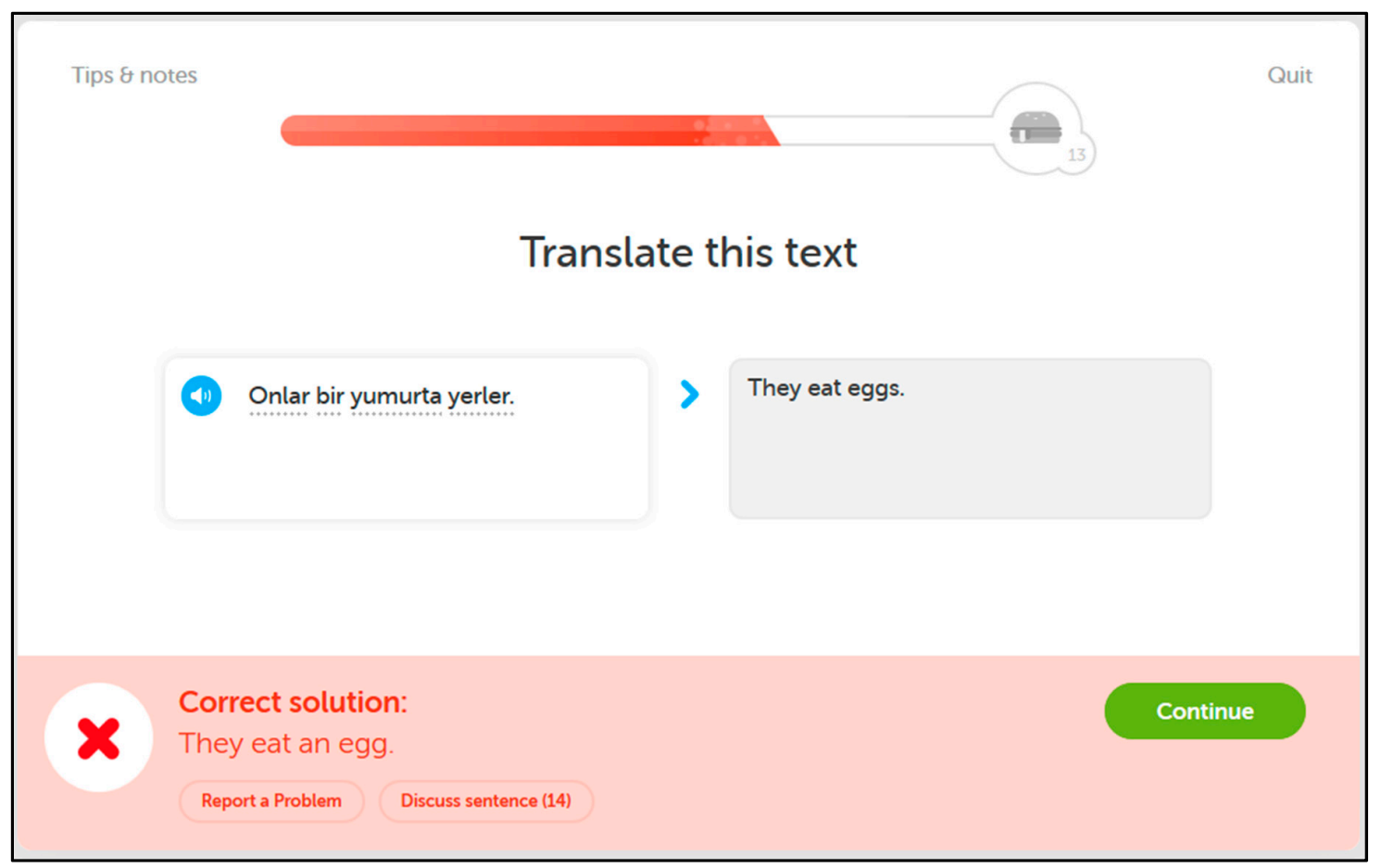

Figure 2. A translation exercise with corrective feedback. Screenshot used with permission from Duolingo, Inc. 


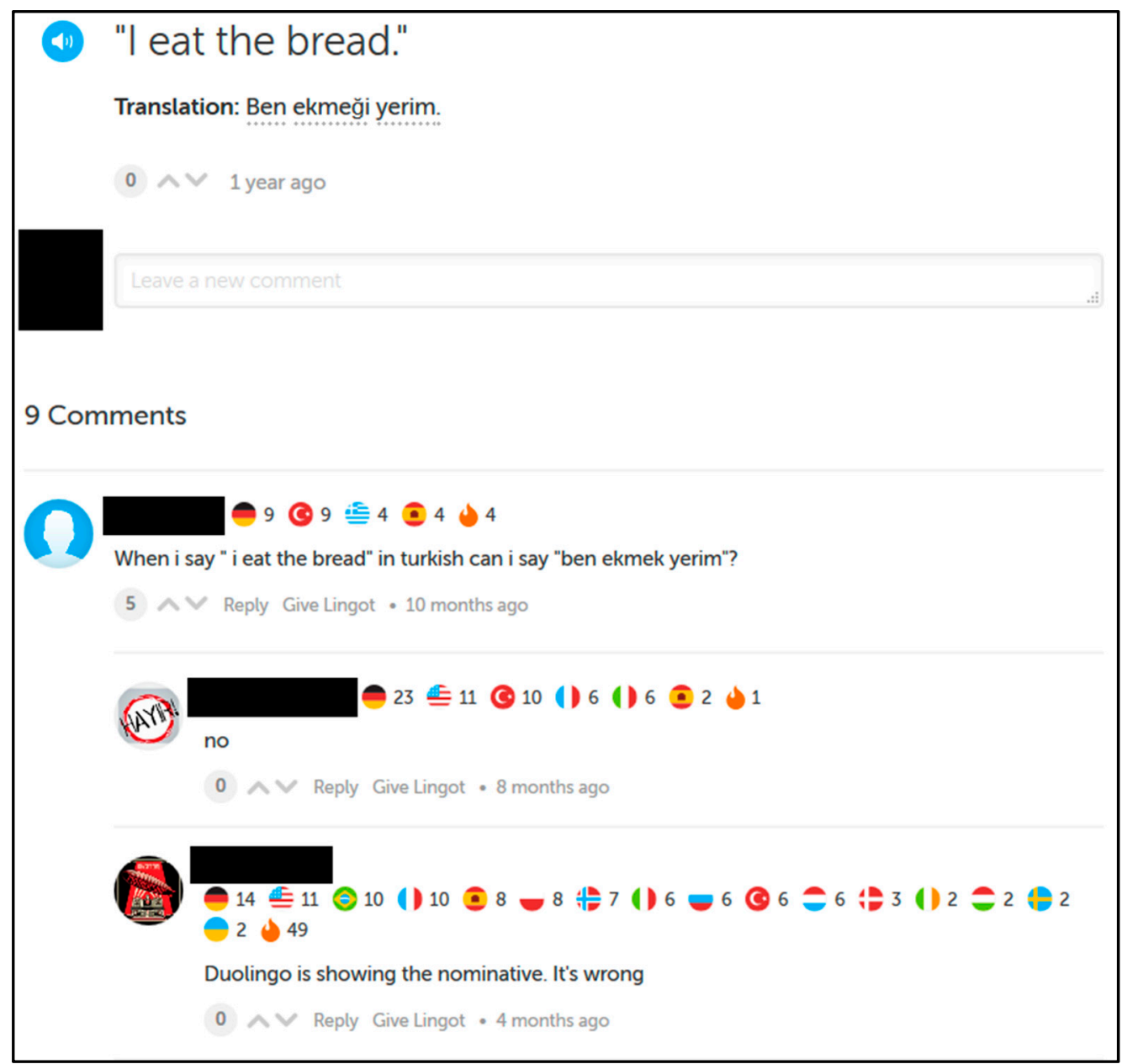

Figure 3. A discussion page connected to an exercise. Screenshot used with permission from Duolingo, Inc.

\subsection{Participants}

Three graduate students partaking in the larger Duolingo challenge were the participants in the current study: Dan, Hima, and Rachelle. They all had experience in second language teaching and learning, and had also studied second language acquisition at the graduate level. Each consented to participate in the study and share their experiences. Their individual backgrounds are detailed next.

Dan is an American graduate student in his early thirties pursuing a PhD. English is his first language, and he is a Korean L2 user (intermediate proficiency). He began learning Korean in his early twenties while teaching English in Korea, and he continues study to this day. His first experience with second language learning was German in high school, which was abandoned when he went to university. Dan has taught English as a second/foreign language for over five years and previously earned a master's in TESOL. During the time of the Turkish study, he was taking a full load of graduate courses and also taught an undergraduate course on language teaching methods.

Hima is a South-Asian female Ph.D. student in her early thirties who speaks a dialect of Nepali as her first language and standard Nepali as her second language, which she learned in school. She learned Hindi as her third language through TV, radio, and communication with Hindi speakers in her late childhood. English, her fourth language, was taught as a foreign language in the schools of Nepal. She learned French as another foreign language but completed only one course. Turkish, a new language for Hima, is the only language that she has learned through a self-paced computer program. In her professional life, Hima has six years of experience teaching English as a foreign language 
and six years teaching different subjects such as methods of language teaching, psycholinguistics, sociolinguistics, and grammar and phonology, at the university level in her home country.

Rachelle, an American graduate student in her late twenties, was pursuing a master's in TESOL. She speaks English as her first language and French is her second, having learned French as the medium of instruction in a Belgian school in Rwanda for six years. She also studied Spanish as a foreign language in high school but has had little exposure to the language since. She taught English as a foreign language in South Korea and started learning Korean while there. However, her proficiency in Korean has dropped to a high novice level since leaving South Korea. She studies Korean autonomously on an irregular basis and is exposed to at least an hour of input once a week.

\subsection{Data Collection and Analysis}

The Duolingo challenge began in late January, 2016 and continued through the middle of April, for a total of 12 weeks of study. Participants kept a daily log of how many minutes they studied, and at the end of each week they answered a set of questions (Appendix A) to reflect on their learning and connect their experiences to ISLA theory. Additionally, they kept more detailed diaries of their day-to-day experiences. These diaries and weekly reflections were comprised primarily of written text $($ Dan $=15,636$ words, Hima $=12,380$ words, Rachelle $=12,828$ words), but also included in situ Duolingo screenshots.

Following the Turkish 101 final exam towards the end of the semester, each researcher-participant reviewed their logs and engaged in multiple readings of their journals. These re-readings allowed for self-reflection, leading to a collected understanding of developments in their experiences over time. After this reflection, they entered a narrative analysis [6] phase where they composed their narratives as a means of analyzing their journals and log data. In addition to consolidating their experiences, constructing the narratives enabled them to unearth "hidden feelings, forgotten motivations, and suppressed emotions" [31] (p. 261). They all wrote in the first person, used an informal style, and ended up with narratives of similar length: Dan $=1803$ words; Hima $=1779$ words; Rachelle $=1583$ words (full narratives available in Supplement S1).

After writing their individual narratives, they shared their stories with one another. Each member of the team read through the other two narratives, highlighting similarities and differences across experiences [10]. This cross-case phase of analysis can be considered analysis of narratives [6], with a goal of extracting themes across stories. The researcher-participants discussed their readings of the narratives, exploring where their narratives converged and diverged, and in the process achieved a richer understanding of their collective experiences. This collaborative process of analysis also represents the primary 'map' followed in reflexive evaluation, whereby mutual collaboration moved the researcher-participants from "subjective biases towards representing multiple voices" [32] (p. 219). Due to length, complete narratives are not included in the body of this article. Rather, in the following section, we provide summaries which highlight the timeline of the Turkish learning experience. Next, the salient themes of ecologically-mediated strategy use and varying degrees of persistence across timescales are elaborated by drawing on similarities and differences across their narratives.

\section{Results}

\subsection{Learning Turkish on Duolingo: Three Stories}

This section presents a summary of the data from the three researcher-participants. These summaries are based on the narratives resulting from the daily journals and weekly reflections. This section is followed by thematic interpretation of the narratives.

Beginning in late January and continuing through mid-April (12 weeks), Dan, Hima, and Rachelle endeavored to learn Turkish on Duolingo. During this period, Dan completed $34 \mathrm{~h}$ of study, Hima completed $22.5 \mathrm{~h}$, and Rachelle completed $15.6 \mathrm{~h}$. These hours were not spread evenly over the 
12 weeks. Figure 4 charts the time each learner spent studying each week, and provides a useful visual aid for interpreting and contextualizing the summaries of their narratives which follow.

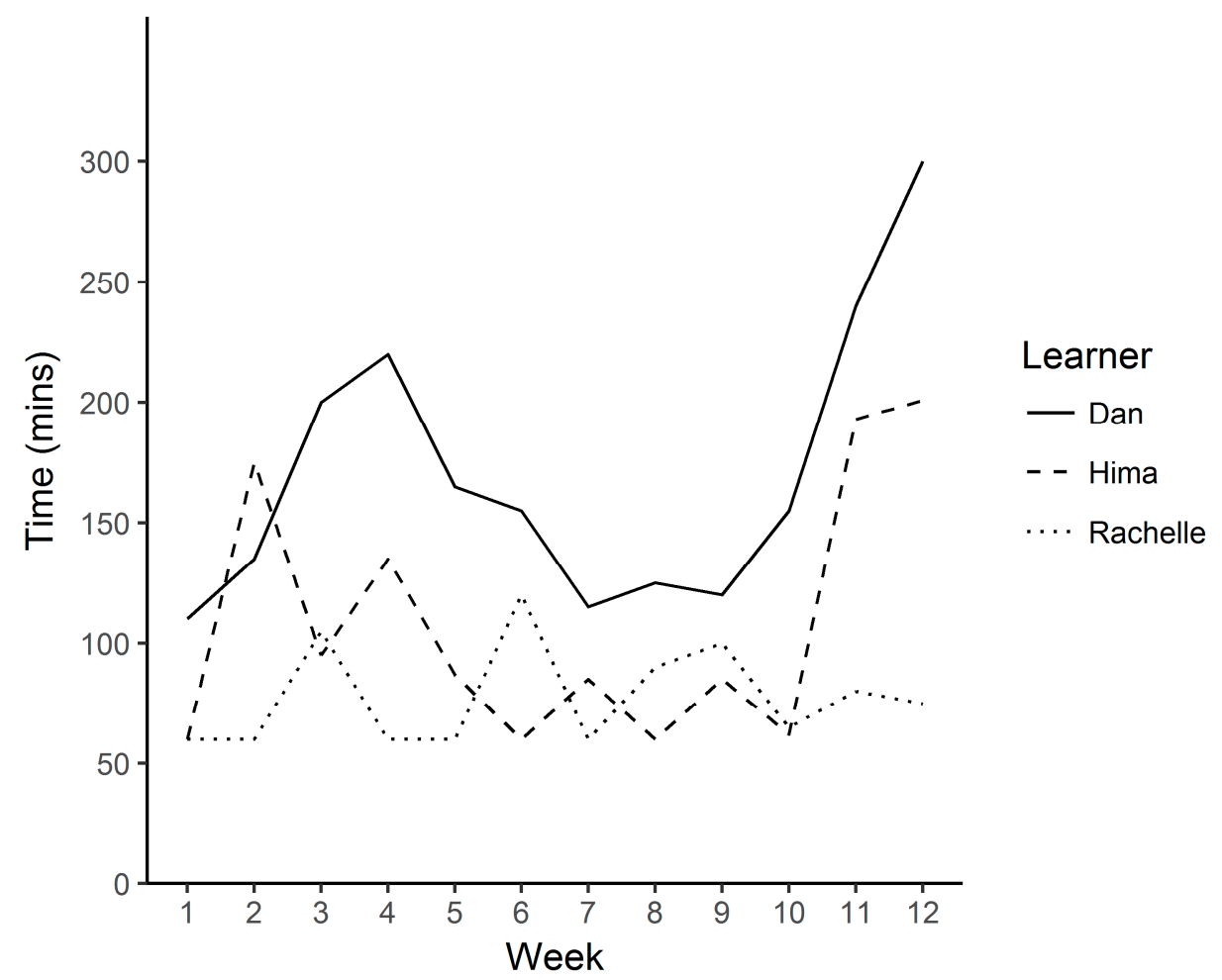

Figure 4. Turkish study time each week of the project.

With all three Turkish learners starting from no experience with the language, their language learning achievement at the end of the 12 weeks is another useful point of reference. On the Turkish 101 final exam, Dan received a score of $64 \%$, Hima received a score of $57 \%$, and Rachelle received a score of $32 \%$. In the context of an introductory Turkish course at the university, all three scores would be interpreted as failing. These relatively low scores may be partially attributable to a mismatch between Turkish 101 content and what learners were provided in the Duolingo course. In the context of the Duolingo challenge reported in the present study, the average score for all nine graduate student learners was $43 \%$, which makes Dan and Hima above-average. In terms of the program-internal Duolingo Progress Test with a possible 5 points, Dan scored 1.78, Hima 1.13, and Rachelle 1.0, with a class average of 0.78 . The Duolingo website lacks any explanation of Progress Test scores, which limits interpretations.

\subsubsection{Dan}

Dan started Duolingo at a brisk pace. He set a "regular" daily goal of 20 experience points (XP) on the program, and quickly completed many early skills, generally studying for 10-25 min every evening before bed. He picked up common phrases, pronouns, and verbs like yer 'eat' and ic 'drink'. After a week or two, he noticed that he struggled to recall previously learned vocabulary and structures, so he started to begin each study session by reviewing previous lessons. At three weeks in, Dan was following his classmates on Duolingo and paying attention to their weekly XP totals. Dan's semester was starting to get busier; nonetheless he increased his study time each week through the first four weeks. After $10 \mathrm{~h}$ of study, Dan took the Duolingo Progress Test and received a score of $0.62 / 5.00$. He did not know what that meant; the score did not seem to match any particular part of the curriculum nor did it come with any explanation. 
In late February, life was getting busier for Dan, and his Turkish study time decreased. He shifted his focus to accumulating XP quickly in order to maintain his streak. In early March, Dan spent some of his lingots to unlock the Timed Practice function. This function had greater XP rewards, and Dan was now able to more quickly reach his daily XP goal. Soon after, Dan and his wife took a short trip to Chicago, and Dan's streak was lost.

After Spring Break, Dan's semester remained busy. Nonetheless, he became very competitive in terms of accumulating XP. By this point, Dan had optimized an approach to earning XP, which he referred to as "grinding" (a term for tedious accrual of resources/rewards in video games). He was less engaged with language learning and more focused on competition; he also began counting down hours until the target of 34 .

In late March, the larger group reached a consensus that they should progress to at least the past tense skill. Dan reached this target quickly. This momentum was interrupted on a busy day in early April when Dan lost his streak. Dan also felt his learning so far had been hollow; he struggled with numbers past five and phrases like Iyi şanslar! ('Good luck!').

After this low point, around the ninth week, Dan changed his approach. His focus shifted from "winning" the weekly XP total to "review [ing] everything, especially early material, extensively" and reaching the $34 \mathrm{~h}$ target. He dramatically increased his weekly study time (up to $5 \mathrm{~h}$ in week 12 ) and completed a large number of review lessons; he did not go much further than the past tense skill. On his last day, he reviewed material and took the Progress Test again, scoring a 1.78/5.00 (he still did not know what that score meant).

With $34 \mathrm{~h}$ of study completed, the in-person Turkish 101 test finally came. He wanted to do well on the test, and even though he earned a D grade (64\%), he was satisfied with his achievement: he ended up with the highest score in the group. However, he decided against continuing to learn Turkish on Duolingo, citing a lack of connection to meaningful use.

\subsubsection{Hima}

Hima started learning Turkish on Duolingo with a goal to achieve the $34 \mathrm{~h}$ target in 15 weeks. For this, she planned to learn Turkish for at least two hours a week. For the first three weeks, she practiced for two or three days a week, setting aside about half an hour at every sitting. However, she practiced Turkish on Duolingo less frequently after about three weeks and would only spend an hour or so towards the end of the week to complete her weekly reflection. The length and frequency of her practice fluctuated for several weeks, but towards the end of the semester, she spent significantly more time because she wanted to reach the past tense skill on Duolingo, as this was the goal for the final exam. This asymmetry in the frequency and length of her time allotment in learning Turkish on Duolingo was the result of her decreasing motivation over time due to the routinized pattern of lessons on Duolingo. Her study and work related roles of a graduate student and her parental roles at home were her excuses for postponing the learning of Turkish on Duolingo towards the end of each week.

In the beginning weeks, Hima reviewed her lessons before starting any new lesson. However, since it would take her some time to do that and since she wanted to move ahead and complete two or three new lessons at every sitting, she would just skim through her notes and continue learning the new lessons. Similarly, she approached the lessons on her own rather than depending upon the explicit rules given in the beginning of new topics on Duolingo. She wrote:

\section{Excerpt 1-Hima}

When I started my lessons, I used to read the "tips and notes" given in the beginning of each new set of lessons. However, I occasionally read them in the later weeks because although I am fond of explicit rules, I wanted to figure out the rules from the example sentences presented in the lessons on my own. Gradually, I started matching the rules I would induce with the rules given in the beginning of the lessons and I still preferred to go with my own learning of the rules instead of reading the tips provided by Duolingo. 
Although in the beginning, she wanted to learn Turkish seriously, there was a gradual change in her goal. She wanted to earn lingots, increase her XP, and review her notes for the exam. She managed to complete only $22 \mathrm{~h}$ of Turkish study before the exam. Although she did not perform very well, her overall score (57\%) was not as bad as she had expected after such passive and routinized study. She wanted to continue learning Turkish after the semester was over in order to achieve the $34 \mathrm{~h}$ goal despite her decreased level of interest in the repetitive Duolingo lessons.

\subsubsection{Rachelle}

Rachelle began learning Turkish intending to reach the 34-h goal. However, she only achieved a one-hour weekly minimum, owing to her other projects as a graduate student. These sessions were usually accomplished once a week, all in one sitting. She wrote:

\section{Excerpt 2-Rachelle}

I thought that I should try to spread my time throughout the week and try to do a little every day and keep a streak going but that never happened. I didn't feel like I was taking it seriously enough if I did that [studying for a short amount of time each day]. I would always have to get my notebook out and it was just easier to set aside a whole hour at a time to study rather than smaller increments of time.

There were a few occasions when Rachelle surpassed the average 60-minute weekly sessions. In one instance, she achieved a full two hours of study time, which she attributed to being on a road trip during spring break, with some extra time at her disposal. During the last few weeks of the semester, she devoted a little more time to Turkish with the approaching exam.

Throughout the language learning experience, she began each session the same: first, reviewing her detailed notes and then reviewing on the Duolingo app itself. She kept a notebook in which she tracked vocabulary, pronunciation, and grammar. She used these notes to induce grammar rules on her own. She spent almost equal amounts of time reviewing and rewriting her notes as she did on Duolingo itself. Her use of the app increased in the weeks leading up to the test as she tried to overtake a classmate in XP.

Rachelle reached only a little over 15 hours of study before taking the final exam. Although she had not spent much time, she performed relatively well on the Duolingo Progress Test and even better than some of her peers who had spent more hours on Duolingo. She planned to continue to reach the 34-h goal after the semester.

\subsection{Ecologically-Mediated Strategy Use}

One theme emerging from the three narratives was ecologically-mediated strategy use, meaning that the use of language learning strategies (LLS) was shaped both by learner-internal factors and environmental factors. In an ecological perspective, "not only do language and learner matter, but so do place, time, others, goals, and motives" [28] (p. 25), and applying this perspective speaks to recent calls for integration of socio-cultural perspectives, learning context, and the learner in LLS research [33]. In the current study, the participants' strategy use was mediated by the learning ecology: the range of available affordances in Duolingo as well as contextual factors related to personal and group obligations affected the suitability of strategies, influencing the choices made by learners.

LLSs are specific actions, behaviors, steps, or techniques that learners employ-often consciously - to improve their own progress in internalizing, storing, retrieving, and using the L2 [34]. LLSs are the tools for active, self-directed involvement that are necessary for developing L2 communicative ability [35]. Several examples of cognitive LLSs appeared in our narratives. Cognitive strategies are the conscious efforts that L2 learners make to achieve their goals in language learning. Some examples of cognitive strategies are repetition, translation, referencing, note-taking, memorization, and deduction [36,37]. Faced with limited support on Duolingo, limited exposure to 
the language, and limited time (i.e., environmental factors), the researcher-participants selected LLSs to meet their specific needs in context.

\subsubsection{Existing Linguistic and Cultural Resources}

One such LLS was the use of pre-existing linguistic resources and cultural knowledge. Each researcher-participant was learning Turkish as at least a third language; therefore, at times, they found themselves resorting to their first or second language knowledge either to understand certain concepts in Turkish or to make form-meaning connections for lexical items. Although the word order in both Dan and Rachelle's first language (i.e., English) was Subject-Verb-Object (SVO), they quickly made a connection between the SOV pattern in Turkish and their second language, Korean, which also allows the SOV pattern. On the other hand, Hima associated the Turkish SOV word order with her first language, Nepali, and her second language, Hindi, both of which allow SOV word order. While this sort of linguistic comparison is not uncommon for learners in a variety of learning contexts, the lack of a human expert to consult as well as a lack of explicit linguistic explanation in the mobile Duolingo platform may have pushed the participants to draw more heavily on their own pre-existing knowledge of other languages.

Furthermore, all participants used LLSs to memorize the meanings of words by utilizing their pre-existing resources. For example, Dan wrote:

Excerpt 3-Dan

I was happy to ... create mnemonics for other words (such as connecting the word for 'lion', aslan, to The Chronicles of Narnia).

Rachelle's strategy was in line with Dan's. She wrote:

\section{Excerpt 4-Rachelle}

I got excited when I could make associations between Turkish and my L2s or something else. I connected portakal 'orange' with the movie, My Big Fat Greek Wedding and then aslan 'lion' with The Chronicles of Narnia.

Both of these excerpts show that Dan and Rachelle associated the meanings of words with their existing cultural schemata, tapping into popular media references as a mnemonic strategy. Likewise, Hima's strategy of memorizing the words was to link the meanings of Turkish words with her available linguistic or non-linguistic schemata. She memorized some Turkish words easily as they were similar to her second language, Hindi, such as kitap for 'book'. She would resort to Nepali, her first language, whenever she had to think of some words, for example, the color terms, numbers, clothes, and food items. Describing an example of using Nepali with the keyword technique [38], she wrote:

\section{Excerpt 5-Hima}

I tried to memorize the Turkish words by making some connections with their equivalent terms in Nepali. For example, I associated the Turkish color word mavi 'blue' with the Nepali word neelo 'blue' by associating it with the color of my secondary school building which used to be blue. The meaning of mavi in Nepali is similar to the meaning of secondary school.

Although the researcher-participants relied on their diverse linguistic backgrounds and other schemata idiosyncratically, one commonality was a need to compensate for the general lack of access to Turkish speakers or Turkish-speaking culture. While Churchill [14], Casanave [8], and Simon-Maeda [9] reported querying L1 Japanese informants (a social strategy) and associating words with Japanese media, in this Duolingo-limited learning these resources were not easily accessible or utilized (despite Duolingo's comment function, which allows users to ask questions or leave comments on exercises). Despite the potential affordances of modern technology to connect people and access media, the researcher-participants were cut off from the streetside conversations and rich literature 
that characterized Spitzer's experience of learning Turkish in the early 20th century [1]. The use of multilingual knowledge and references to the participants' own pop cultures, rather than Turkish language and culture, is reflective of this isolation in the Duolingo learning context, and due to the challenge of using only Duolingo for study, the researcher-participants could not avail themselves of other Turkish resources.

\subsubsection{Efficiency}

The researcher-participants also reacted to Duolingo's affordances for language study in different ways. Dan, early on, found himself relying on mouse-overs to get translations and other strategies for quickly working through exercises. The instant L1-L2 glossing of mouse-overs is an affordance not found in traditional language classrooms or available in most L2 use situations, yet Dan adopted the mouse-over strategy quickly and enthusiastically in the Duolingo environment. Elaborating on his choices of in-lesson strategies, he wrote,

Excerpt 6-Dan

I continued to optimize my strategies for getting through exercises-process of elimination and scanning for key words in multiple choice items, focusing on subject-verb agreements for fill-in-the-blank, looking for mechanics cues (i.e., capital letters) on mobile platform sentence scrambles [translations with word banks], and so on.

Excerpt 6 shows how Dan's deployment of strategies in Duolingo lessons was often in response to its unique gamified elements and a desire to conserve his limited time resources. Hima also used a somewhat similar strategy of clicking on words to figure out their meanings in order to save time. She wrote:

\section{Excerpt 7-Hima}

I figured out that Duolingo introduced new words in each lesson using different color, mostly yellow, that prompted me to draw the mouse over those words, see their meanings and figure out the meanings of entire sentences. That saved me a lot of time.

While Grabe reported using a bilingual dictionary to support his Portuguese word learning [12] and Churchill [14] also did so to develop more accurate semantic knowledge of saiketsu, 'to draw blood', the L1-L2 mouse-over glosses in Duolingo required no search and limited evaluation (some mouse-overs displayed multiple translations), predicting weak learning outcomes based on Laufer and Hulstijn's Involvement Load Hypothesis [39]. In this environment, the participants needed other strategies to support their learning, such as note-taking.

\subsubsection{Note-Taking}

One LLS preferred by Hima and Rachelle was to keep pen-and-paper notes of the things learned with each lesson. This note-taking strategy is an example of a cognitive strategy [40], and one that appeared to be effective. Although Hima completed 11.5 fewer hours of study (i.e., one-third less) than Dan, she trailed him by less than $8 \%$ on the Turkish final exam. Hima took notes of the words and new grammatical structures from the very beginning of her Turkish lessons, but she did not separate and organize them into different sections. Hima kept simple notes of the Turkish sentences provided on Duolingo with their English translations so that she could review them before responding to questions in lessons. Rachelle, on the other hand, not only kept notes but also organized them in different sections and rewrote those notes for her convenience, as detailed in Excerpt 8:

Excerpt 8-Rachelle

I knew right away that I would need a notebook and from the very first lesson, I was ready with my notebook and began writing down phrases, vocabulary words, and notes to myself. By the third week, I had already rewritten my notes three times. As I advanced 
through the lessons, I began to make categories for each new vocabulary word and phrase I learned. I had already started a "Vocabulary" section, "Phrases", and "Grammar". If my notes got too jumbled, I would rewrite and reorganize them to my satisfaction to help me reorganize my thoughts and it served as a great way to review as well.

Despite the fact that Rachelle spent less time studying than many of her peers, she performed better than some who had studied longer. Her performance may be partially attributable to her strategy of organized note-taking, similar to the usage-oriented note-taking strategies adopted by learners in learning vocabulary in $\mathrm{Gu}$ and Johnson [40]. Despite the potential of integrated note-taking in CALL and MALL [18], Duolingo lacked this feature, and both Rachelle and Hima resorted to old-fashioned, yet still portable, handwritten notes to consolidate their learning.

\subsubsection{Goal-Setting}

The learning situation also influenced the participants' metacognitive strategy use. Metacognitive strategies are used by learners to "oversee, regulate, or self-direct their language learning" [41] (p. 5). Metacognitive strategies are also called management strategies as they help learners plan, monitor, and evaluate their learning. Although the larger group goal was to reach $34 \mathrm{~h}$ of study, the three researcher-participants set long-term and short-term goals in different ways. Dan aimed for the $34 \mathrm{~h}$ goal and he achieved it by carefully monitoring his time spent and planning accordingly. Hima completed only $22 \mathrm{~h}$ despite her wish to accomplish more. Rachelle, however, followed her own pace and focused more on understanding and learning the lessons in detail rather than completing more hours on Duolingo. Dan often planned to "win" the weekly XP total among the larger group, and directed his study in a way that would enable him to do so efficiently. Rachelle initially focused on learning the material and evaluating her understanding of it, but towards the end of the 12 weeks (with a deadline approaching) also began to monitor her XP totals, showing how changing ecological forces can interact with learner metacognition.

To summarize, the researcher-participants readily used their pre-existing linguistic and cultural knowledge. Their strategy choices were often in response to constraints and affordances in their learning environment, ranging from Duolingo features and limitations to group competition and obligation. These ecological forces also shaped their metacognitive strategizing, impacting their goal-setting and plans made to achieve those goals, as well as how they monitored and evaluated their progress.

\subsection{Varying Degrees of Persistence across Timescales}

Across the three accounts, characterizations of persistence evolved and varied according to timescale. Persistence, which can generally be conceptualized as "the behavior of continuing action despite the presence of obstacles" [42] (p. 1), represents concrete action rather than internal psychological forces. Timescales refer to heterochrony across processes [43], and allow constructs or phenomena (i.e., persistence) to be scaled according to temporal perspectives. Timescales can thus account for dynamicity within the learning ecology and introduce a historical perspective. The three researcher-participants started the semester with the intentions of studying for $34 \mathrm{~h}$, or at the very least, a minimum of an hour every week. Nonetheless, their short-term persistence towards that goal varied considerably; Figure 4 provides a visual representation of their degrees of persistence across short-term timescales.

Motivating and demotivating factors influenced their short-term persistence in learning Turkish on Duolingo. Motivation is generally viewed to be directly related to persistence. However, Norton's idea of investment goes beyond motivation, involving expenditure of capital (e.g., time, money) alongside motivation to learn [44]. For example, someone motivated to learn a language may not actually invest in doing so. In this sense, persistence goes beyond motivation: one expends time and effort, or learning does not happen. In the present study, one of the demotivating factors was the format of the language learning context itself (similar to Clark and Gruba [16]). All three wrote of 
frustrations with the audio quality of Duolingo's aural input and the repeated pattern of exercises. Rachelle wrote:

\section{Excerpt 9-Rachelle}

I had expected that the pronunciation would be computerized but I was still quite disappointed when I heard the stilted robotic voice.

While Rachelle's demotivation resulted from the quality of aural input, Hima realized that Duolingo's pedagogical approach, especially its use of a limited range of learning activities, played a part in her demotivation.

\section{Excerpt 10-Hima}

At times, I wondered why I was so demotivated in learning Turkish on Duolingo. This might be because as a language teacher, I was exposed to a lot of teaching techniques and activities to teach different aspects of language. I had expected that Duolingo would make use of at least some of the activities [I had been exposed to before] but [having] only the same routinized practice and input was enough for me to have a thought of giving up.

Despite these annoyances, the researcher-participants continued to pursue learning, primarily due to their obligation to a graded group project, highlighting a powerful ecological influence on persistence. The group obligation facilitated maintaining persistence over a longer time period in spite of several demotivating Duolingo features cited by the researcher-participants. At the same time, the negative influences of those features contributed to limited degrees of persistence in the short-term: reaching the minimal study time commitment each week rather than spending time in accordance with a language learning goal.

There were, however, some moments of relief among the frustrations of the learning context. Dan and Rachelle found popular media references to bring some amusement to the learning process, making persisting more bearable. Dan wrote:

\section{Excerpt 11-Dan}

Absurd sentences like "The duck speaks Italian" only affirmed the lack of relevance [of the learning exercises], although the occasional Game of Thrones [fantasy television program] and James Bond [spy-thriller movie franchise] references elicited much needed chuckles.

Most of these references were to the researcher-participants' own cultural backgrounds and experiences; Duolingo did little to build their motivation by introducing Turkish-speaking culture or media, even when there were opportunities to do so. For example, when Duolingo presented the sentence 'My name is red' for learners to translate, they initially thought it was just another low-context absurdity (like 'The duck speaks Italian'), not knowing it was actually the title of a famous Turkish novel (Benim Adım Kırmızı by Nobel-laureate Orhan Pamuk).

Duolingo's gamification also provided some motivation to persist. Dan and Hima discussed the incentives of lingots and XP. Dan, in particular, seemed to be highly motivated to build streaks in Duolingo and made a competition out of accumulating XP each week:

\section{Excerpt 12-Dan}

I also decided to follow my classmates on Duolingo. This created competition by displaying how much [sic] experience points each person had accumulated each week, which I likednow I had a short-term goal. The (lapsed) gamer in me definitely wanted to "win" this.

On the other hand, Rachelle mostly avoided competition and continued to progress at a slower rate, meeting minimum requirements:

\section{Excerpt 13-Rachelle}

I put it on my weekly checklist and especially during the first half, would study at the last minute on Sunday because it felt like a chore that needed to be checked off. 
These clashing orientations to competition challenged Duolingo's highly gamified learning approach. What motivated Dan, and ultimately contributed to his observed persistence in the learning enterprise, was less important to Rachelle and Hima. At the same time, the language learning utility of Dan's greater persistence was at times questionable: after an extended period of "grinding" XP, Dan had a poor self-assessment of his Turkish ability, though he was able to rectify his situation somewhat in the final weeks of study.

As the semester progressed, with increasing duties as graduate students and other obligations, all three found it difficult to maintain momentum. As Dan wrote:

\section{Excerpt 14-Dan}

Real life was seeping in and affecting my experience, too: my semester was ramping up, and finding time for Duolingo, not to mention energy or enthusiasm, was more and more of a challenge.

In addition, other events, such as spring break, changed their patterns of persistence. For Dan, it caused him to lose his streak when he took a trip. Hima postponed her study session till the end of the week rather than spreading it out. Meanwhile, Rachelle reached her highest weekly total, two hours of study time, due to having free time. We see parallels here with the persistence problems faced by Nielsen's U.S. government employees, who noted travel and lack of time as major obstacles in their attempt to learn a foreign language in a self-directed CALL context [25].

Though they all noted their busyness, surmounting frustrations with Duolingo, and decreasing motivation, the researcher-participants persisted and set their own personal goals. Dan and Hima strived to arrive at the past tense in the skills tree before the final exam, as had been discussed among the class. Rachelle, on the contrary, was happy going at her own pace. However, the upcoming exam gave the three a push to increase their $\mathrm{XP}$, amount of study time, and skills. In the weeks leading to the exam, they indicated a greater drive to review and advance to new skills. They were all motivated to both perform well on the exam and surpass their peers in level and XP, and this competition-derived motivation played a particularly formative role in Dan's persistence. These ecological influences (peers, professional obligations, time constraints) seemed to factor just as importantly as Duolingo itself in terms of individual learning persistence in the short-term, if not more so. A parallel could be drawn to the experience of Winkler [15], who persisted through periods of negative feelings and resistance to learning Danish, ultimately subordinating himself to the urging from his peers and requirement of his workplace to learn the language.

Dan completed the $34 \mathrm{~h}$ of study in the twelve weeks of the project, and while Hima did not reach the goal within that timeframe, she did go on to reach the target at a later time. Rachelle, despite initially expressing a desire to continue towards the $34 \mathrm{~h}$ goal, ultimately chose not to do so. The general consensus among them seemed to be that they would like to continue learning Turkish beyond the project if time allowed, but in all likelihood they would not. More definitely, they would not choose to do so solely using Duolingo. With the initial exam completed, they felt little motivation to continue with Duolingo. Just as motivation has been cited as a key factor in long-term persistence in traditional face-to-face instructed language learning [45], it appears that motivation is equally important, if not more so, in long-term persistence in self-directed CALL and MALL.

\section{Discussion}

In this study, researcher narratives shed light on how, and to what degree, adult learners can accomplish the task of foreign language learning on Duolingo. One interesting finding of the study is that although the three researcher-participants varied in their motivation at different stages of learning Turkish, they all persisted in continuing the learning process. Additionally, they differed in terms of their short-term goals and persistence in achieving them. Dan was persistent in practicing nearly every day and in hitting his daily XP target. On the other hand, Hima and Rachelle were persistent in hitting their weekly goal of at least an hour per week, but they studied mostly on weekends. 
In long-term persistence, all the participants made a decision to not go beyond the $34 \mathrm{~h}$ target on Duolingo, which Dan accomplished before the test, whereas Hima and Rachelle planned to continue after the semester to reach the target. Despite their busy schedules and other commitments related to their academic and personal lives, they were invested in achieving specific individual and group goals, and in preparing themselves for the exam. Accordingly, they deployed strategies to support their Turkish learning on Duolingo, both in response to the affordances and constraints of the program as well as the aforementioned goals and limitations on their time. This supports Oxford and Shearin's claim that the "L2 learning strategies that students use are influenced by goals, expectancies and self-efficacy" [46] (p. 21), and further demonstrates how ecological factors drove strategy use.

The participants in this study were invested [44] and persistent in continuing their learning despite their decreasing levels of motivation and frustrations with Duolingo materials. Dan, Hima, and Rachelle vented their frustrations with the way Duolingo presented the learning materials, e.g., its "stilted robotic voice" in Rachelle's words, "the same routinized patterns" in Hima's opinion, and frequent "absurd sentences" in Dan's words, but discovered motivation from other sources. Dan's approach of following his friends and striving to stand out among them highlights a sense of his persistent investment, and all three of them persisted in response to their obligations to their peers and to the class project, to varying degrees.

It is worth noting that participants in this study may not be considered typical Duolingo users: their prior language learning experience (Hima in particular) and knowledge of second language learning and teaching likely exceed that of the average Duolingo learner. Similarly, many Duolingo users may lack the external obligations to use the program. However, this apparent limitation, in terms of generalizability, provides a useful, positively-skewed perspective. Namely, the language learning outcomes of the experienced, motivated participants in this study represent the upper end of what might be reasonably expected. Consequently, expectations for Duolingo users without previous language learning experience or sufficient motivation should be tempered accordingly.

Despite being constantly connected to the internet when using Duolingo, the learners in this study experienced a high degree of isolation from Turkish language and culture. Unlike other language learning researcher-narratives (e.g., Duff et al. [10], who made connections to discourses of Sinology and the politics of Chinese-speaking nations), the participants in this study could not position themselves in a larger context of Turkish speakers. This isolation is an interesting finding in its own right, given the internet's potential for connecting learners with other users of the language and creating new identities [47].

Although the context for this study differed from the immersion-based language learning reported in many researcher narratives, it illuminates foreign language learning experiences in a self-directed CALL/MALL context. This study, however, is not without limitations. For example, the study is limited by its relatively short period of data collection, especially when considering findings related to persistence varying across timescales. While three months is above average for SLA studies generally, many narrative studies fruitfully involve even longer periods of time. Another limitation is the artificial constraints on self-directed learning imposed by the larger group project. Typical users of Duolingo may seek external opportunities to support their language learning (we would hope that they do), but the three participants in this study did not (which may nevertheless mirror some learners' use of the program). However, the decision to limit learning to Duolingo combined with the final exam administered at the close of the time period allowed for controlled evaluation of the primary learning materials, in line with similar studies of learning with CALL/MALL programs $[16,22,23,25]$. Finally, the study was constrained by the choice of Turkish as the target language: Outside of being interested in language learning and in carrying out the project (the latter not typical in most language learning contexts), we had little integrative motivation to learn the language. Also, our experiences were based only on Duolingo's Turkish course, which appears to be less developed than more commonly studied languages such as Spanish and French. It should be noted that since the conclusion of this study, 
Duolingo has initiated several new features, including language clubs in which individuals can connect and compete with other Duolingo users.

On a methodological note, this study examined three language learning experiences on Duolingo from a narrative perspective, involving both narrative inquiry and narrative analysis. The latter stage involved cross-case comparisons, which offered "multiple lenses through which the learners' experiences can be viewed and interpreted" [10] (p. 143). Furthermore, the narratives' temporal sensitivity afforded consideration of short-term and long-term persistence and the varying strategy use across timescales. This narrative approach thus yielded valuable insights; however, more qualitative and quantitative research studies are needed to better understand the experiences of self-directed learners in CALL/MALL settings and to determine the effectiveness of online language learning programs. In particular, we encourage the L2 research community to engage with large-scale commercial CALL programs, which are substantially under-investigated considering how many individuals around the globe use them, solely or in a supplementary fashion, to pursue their language learning goals. If the researcher-participants' experiences with one such CALL/MALL program are any indication, evaluative research may be critically needed to improve learner experiences.

More specifically, we are able to offer several targets for improvement based on the findings of this study. First, a primary reliance on decontextualized grammar-translation exercises and audiolingual drilling in a language learning program contributed to limited achievement and learner frustration, which ultimately resulted in a lack of long-term persistence. CALL and MALL program developers should aim for instructional formats featuring some degree of context and meaningful communication. Second, the social aspects of Duolingo were promising in some ways, but limited in many others. The simple act of following friends inspired competition, which in turn promoted completing more lessons. However, there was virtually no opportunity to actually communicate in Turkish, forfeiting a significant learning and motivational opportunity. Finally, the limited feedback and focus on scores, points, and levels as indicators of progress could be improved. For example, an explanation of what levels and Progress Test scores mean (e.g., material learned, knowledge of vocabulary) would be informative for learners and may help them set more meaningful learning goals.

We also have recommendations for language learners and teachers. First, learners are advised to seek social support in achieving their learning goals in Duolingo by linking up with friends and following each other's achievements and XP totals. Teachers can foster this social support by using Duolingo's classroom function and helping students set appropriate goals in the program. Second, based on our experiences, we can only recommend Duolingo as a learning supplement. On its own, Duolingo lacks several key affordances for language learning, but on the other hand, we did learn some Turkish, and in particular we found it helpful for establishing basic form-meaning connections in vocabulary learning. Foreign language learners in particular can take advantage of Duolingo's portability to augment their learning efforts wherever and whenever an opportunity arises.

In the future, we hope that continuous researcher engagement and developer revision efforts will lead to self-directed CALL- and MALL-based learning that is not just convenient and gamified, but less frustrating, more fruitful, and more ubiquitous.

Supplementary Materials: The following are available online at www.mdpi.com/2226-471X/2/2/4/s1, Supplement S1: Full Narratives.

Acknowledgments: No funding was received in support of this work. We are grateful to two anonymous reviewers and the editors for their helpful and insightful comments.

Author Contributions: S.L. conceived and designed the project. D.I., H.R., and R.O. completed the learning on Duolingo as researcher-participants. D.I., H.R., and R.O. analyzed the data. D.I., H.R., R.O., and S.L. wrote the paper.

Conflicts of Interest: The authors declare no conflict of interest. 


\section{Appendix A}

Weekly Log and Reflection Questions

Q1 What levels did you complete this week (e.g., Basic 2 (levels 1-3))?

Q2 Did you use the Review function this week? Please describe.

Q3 Please summarize what you have learned this week in Turkish.

Q4 What successes have you achieved this week?

Q5 What difficulties have you faced this week?

Q6 Please share any other experiences/thoughts/opinions on your language learning experiences while using Duolingo during the week.

Q7 Please share your insights from your experience with Duolingo in relation to what we discussed in class.

\section{References}

1. Spitzer, L. ; Atak, Tülay, Translator; Learning Turkish. PMLA 2011, 126, 763-779. [CrossRef]

2. Pajak, B. Making Duolingo. What Countries Study Which Languages, and What Can We Learn from It? Available online: http:/ / making.duolingo.com/which-countries-study-which-languages-and-what-canwe-learn-from-it (accessed on 5 May 2016).

3. Benson, P. Narrative Inquiry in Applied Linguistics Research. Annu. Rev. Appl. Linguist. 2014, 34, 154-170. [CrossRef]

4. Barkhuizen, G. Research Timeline: Narrative Research in Language Teaching and Learning. Lang. Teach. 2014, 47, 450-466. [CrossRef]

5. Vasquez, C. TESOL, Teacher Identity, and the Need for "Small Story" Research. TESOL Q. 2011, 45, 535-545. [CrossRef]

6. Barkhuizen, G. Narrative Knowledging in Second Language Teaching and Learning Contexts. In The Handbook of Narrative Analysis; De Fina, A., Georgakopoulou, A., Eds.; John Wiley \& Sons, Inc.: Hoboken, NJ, USA, 2015; pp. 97-115.

7. Schmidt, R.; Frota, S. Developing Basic Conversational Ability in a Second Language: A Case Study of an Adult Learner of Portuguese. In Talking to Learn: Conversation in Second Language Acquisition; Day, R.R., Ed.; Newbury House: Rowley, MA, USA, 1986; pp. 237-326.

8. Casanave, C.P. Diary of a Dabbler: Ecological Influences on an EFL Teacher's Efforts to Study Japanese Informally. TESOL Q. 2012, 46, 642-670. [CrossRef]

9. Simon-Maeda, A. Being and Becoming a Speaker of Japanese: An Autobiographic Account; Multilingual Matters: Buffalo, NY, USA, 2011.

10. Duff, P.; Anderson, T.; Ilnyckyj, R.; van Gaya, E.; Wang, R.T.; Yates, E. Learning Chinese; De Gruyter Mouton: Berlin, Germany, 2013.

11. Watson, C. Small Stories, Positioning Analysis, and the Doing of Professional Identities in Learning to Teach. Narrat. Inq. 2007, 17, 371-389. [CrossRef]

12. Grabe, W.; Stoller, F.L. Reading and Vocabulary Development in a Second Language: A Case Study. In Second Language Vocabulary Acquisition; Coady, J., Huckin, T., Eds.; Cambridge University Press: Cambridge, UK, 1997; pp. 98-122.

13. Carson, J.G.; Longhini, A. Focusing on Learning Styles and Strategies: A Diary Study in an Immersion Setting. Lang. Learn. 2002, 52, 401-438. [CrossRef]

14. Churchill, E. A Dynamic Systems Account of Learning a Word: From Ecology to Form Relations. Appl. Linguist. 2007, 29, 339-358. [CrossRef]

15. Winkler, I. Being me whilst Learning Danish: A Story of Narrative Identity Work during the Process of Learning a Foreign Language. Qual. Res. Org. Manag. Int. J. 2014, 9, 290-307. [CrossRef]

16. Clark, C.; Gruba, P. The Use of Social Networking Sites for Foreign Language Learning: An Autobiographic Study of Livemocha. In Curriculum, Technology \& Transformation for an Unknown Future, Proceedings of the ASCILITE Conference, Sydney, Australia, 5-8 December 2010; Steel, C., Keppell, M., Gerbic, P., Housego, S., Eds.; The University of Queensland: Brisbane, Australia, 2010; pp. 164-173.

17. Levy, M.; Stockwell, G. CALL Dimensions: Options and Issues in Computer-Assisted Language Learning; Lawrence Erlbaum Associates: Mahwah, NJ, USA, 2006. 
18. Rocca, S. iPadding Sixth Graders to Impact Language Learning: An Empirical Mobile Study. IALLT J. 2015, $45,23-43$.

19. Burston, J. MALL: The Pedagogical Challenges. Comput. Assist. Lang. Learn. 2014, 27, 344-357. [CrossRef]

20. Duman, G.; Orhon, G.; Gedik, N. Research Trends in Mobile-Assisted Language Learning from 2000 to 2012. ReCALL 2015, 27, 197-216. [CrossRef]

21. Reinders, H.; Pegrum, M. Supporting Language Learning on the Move: An Evaluative Framework for Mobile Language Learning Resources. In Second Language Acquisition Research and Materials Development for Language Learning; Tomlinson, B., Ed.; Taylor \& Francis: London, UK, 2015; pp. 116-141.

22. Vesselinov, R. Measuring the Effectiveness of Rosetta Stone; Rosetta Stone: Harrisonburg, VA, USA, 2009.

23. Vesselinov, R.; Grego, J. Duolingo Effectiveness Study; City University of New York: New York, NY, USA, 2012.

24. Lord, G. I don't know how to use words in Spanish: Rosetta Stone and Learner Proficiency Outcomes. Mod. Lang. J. 2015, 99, 401-405. [CrossRef]

25. Nielsen, K.B. Self-study with Language Learning Software in the Workplace: What Happens? Lang. Learn. Tech. 2011, 15, 110-129.

26. Duolingo, About Us: Press. Available online: https://www.duolingo.com/press (accessed on 2 May 2016).

27. Cutshall, S. Interview with Duolingo Founder Luis von Ahn. Lang. Educ. 2016, Jan/Feb. 15-17.

28. Lantolf, J.P. Sociocultural Theory and Second Language Learning; Oxford University Press: Oxford, UK, 2000.

29. Kramsch, C.J. Language Acquisition and Language Socialization: Ecological Perspectives; Continuum: London, UK, 2002.

30. Burston, J. The Reality of MALL: Still on the Fringes. CALICO J. 2014, 31, 103-125. [CrossRef]

31. Canagarajah, A.S. Teacher Development in a Global Profession: An Autoethnography. TESOL Q. 2012, 46, 258-279. [CrossRef]

32. Finlay, L. Negotiating the Swamp: The Opportunity and Challenge of Reflexivity in Research Practice. Qual. Res. 2002, 2, 209-230. [CrossRef]

33. Cohen, A.D.; Griffiths, C. Revisiting LLS Research 40 Years later. TESOL Q. 2015, 49, 414-429. [CrossRef]

34. Oxford, R.L. Language Learning Strategies: What Every Teacher Should Know; Newbury House: New York, NY, USA, 1990.

35. O'Malley, J.M.; Chamot, A.U. Learning Strategies in Second Language Acquisition; Cambridge University Press: Cambridge, UK, 1990.

36. O'Malley, J.; Chamot, A.; Stewner-Manzanares, G.; Kupper, L.; Russo, R. Learning Strategies Used by Beginning and Intermediate ESL Students. Lang. Learn. 1985, 35, 21-46. [CrossRef]

37. Rubin, J. Study of Cognitive Processes in Second Language Learning. Appl. Linguist. 1981, 11, 117-131. [CrossRef]

38. Nation, I.S.P. Learning Vocabulary in Another Language, 2nd ed.; Cambridge University Press: Cambridge, UK, 2013.

39. Laufer, B.; Hulstijn, J. Incidental Vocabulary Acquisition in a Second Language: The Construct of Task-Induced Involvement. Appl. Linguist. 2001, 22, 1-26. [CrossRef]

40. Gu, Y.; Johnson, R.K. Vocabulary Learning Strategies and Language Learning Outcomes. Lang. Learn. 1996, 46, 643-679. [CrossRef]

41. Wenden, A.L. Learner Strategies. TESOL Newsl. 1985, 19, 1-4.

42. Rovai, A.P. In Search of Higher Persistence Rates in Distance Education Online Programs. Int. High. Educ. 2003, 6, 1-16. [CrossRef]

43. De Costa, P.I. Scaling Emotions and Identification: Insights from a Scholarship Student. Linguist. Educ. 2016, 34, 22-32. [CrossRef]

44. Norton, B. Identity and Language Learning: Extending the Conversation, 2nd ed.; Multilingual Matters: Bristol, UK, 2013.

45. Ramage, K. Motivational Factors and Persistence in Foreign Language Study. Lang. Learn. 1990, 40, 189-219. [CrossRef]

46. Oxford, R.; J., Shearin. Language Learning Motivation: Expanding the Theoretical Framework. Mod. Lang. J. 1994, 78, 12-27. [CrossRef]

47. Thorne, S.L.; Sauro, S.; Smith, B. Technologies, Identities, and Expressive Activity. Annu. Rev. Appl. Linguist. 2015, 35, 215-233. [CrossRef]

(C) 2017 by the authors. Licensee MDPI, Basel, Switzerland. This article is an open access article distributed under the terms and conditions of the Creative Commons Attribution (CC BY) license (http:/ / creativecommons.org/licenses/by/4.0/). 